Research teams disperse as UK government rethinks Alvey

\section{London}

THE British government's strained efforts to formulate a long-term programme for information technology research appear to have ground to a complete halt amid a wide-ranging internal review at the Department of Trade and Industry (DTI). At present, Britain's information technology research drive is through the DTIcoordinated Alvey programme, launched in 1983 with $£ 200$ million of taxpayer's money (from the budgets of the DTI, the Science and Engineering Research Council and the Ministry of Defence) and $£ 150$ million from private industry. The programme was to last a nominal five years, although all the available funds have now been allocated.

Last July the under-secretary of state at the DTI, John Butcher, publicly pledged government support for a follow-up programme, but details have failed to emerge and researchers in the field are becoming increasingly dispirited over the government's apparent lack of interest. Further gloom will follow next month when a study is published claiming that the $£ 70$ million spent on Alvey's software engineering research has effectively been wasted, and that the programme as a whole was misconceived. The conclusions are at odds with most appraisals of the programme, which indicate that Alvey was on the whole a successful experiment.

Recent movements within the Alvey directorate suggest that if a follow-on programme is approved, its organization will be substantially different from that of its predecessor. In October, Alvey's director, Brian Oakley, retired; his place was officially taken last month by Timothy Walker, until then private secretary to Lord Young, the new minister at the department. At the same time, responsibility for the research side of the DTI's electronic applications division (which supports research into superconductors, opto-electronics, gallium arsenide and molecular electronics) was passed to the Alvey directorate, expanding its size by about half and drawing it into the overall machinery of the DTI. The department is evidently endeavouring to streamline the administration of its collaborative research programmes.

Draft copies of the report attacking the Alvey programme have infuriated many supporters of the programme, not least because it comes from the London Business School's Centre for Business Strategy (CBS), which had a brief but by all accounts acrimonious relationship with Alvey when it was contracted to evaluate various aspects of the programme. After two years, it became apparent that the team and Alvey had different views on what comprised an evaluation, and CBS's official involvement ended. The new report, compiled by Peter Grindley, does not, therefore, have official Alvey status (as the programme's supporters are quick to point out), although it does draw on the information collected by the official evaluators (Grindley was not one of them). The report is an overview of the UK software industry, and touches only briefly on Alvey's role. Nevertheless, it is outspoken in its criticism.

Grindley attacks the programme for focusing on "systems factories", concentrating on software production and efficient coding. Such a policy, says Grindley, amounted to an expensive mistake. "The main opportunities are not in efficient coding but in the solution of broader, unstructured problems within a changing environment. What is needed is more flexibility, not more formalism."

Grindley questions the need for government intervention in software design techniques, arguing that the Alvey programme discouraged British companies from seeking overseas partners, insulating Britain and providing no formal mechanism for the international transfer of technology: "A game of nationalistic noncooperation is one the UK is very poorly placed to win".

Alvey's official evaluators, from policy

\section{Tokyo \& London}

A DETERMined effort by Britain's Cable and Wireless to break into Japan's lucrative international telecommunications market has at last paid off. The Ministry of Post and Telecommunications has granted a licence to International Digital Communications (IDC), a consortium headed by the British company, to operate in competition with two other international telecom companies, the recently privatized monopoly Kokusai Denshin Denva (KDD) and a rival consortium, International Telecommunications Japan (ITJ), led by giant Japanese trading companies.

The decision to grant IDC a licence ends a lengthy battle by Cable and Wireless which at one stage threatened to develop into a major trade dispute between Japan and the United Kingdom. The ministry tried to force a merger between IDC and ITJ which would have considerably diluted Cable and Wireless's shareholding. But the plan foundered on ITJ opposition to IDC's plan to lay a trans-Pacific optical fibre cable. The cable is a key link in Cable and Wireless's planned network of optical fibre

research units at the universities of Manchester and Sussex, do not share Grindley's views. In their interim evaluation report, presented to the DTI in October, the teams concluded that Alvey had generally been successful, with a significant impact on academic research and an increase in collaboration between academic and industrial researchers.

The report stressed the need for a follow-up programme; the delay in an announcement of the government's intentions is already causing research teams to disintegrate. For the academic partners at least, the absence of a government policy is causing frustration and is impeding the formulation of long-term strategy.

A blueprint for an Alvey follow-on was submitted to the DTI in November last year, under the title "IT86" and compiled by a committee headed by Sir Austin Bide. That report recommended a collaborative programme similar to Alvey, but with emphasis on applications (the Alvey programme concentrated on 'precompetitive' research). The government would provide $£ 425$ million, with industry's contribution bringing the total to around $£ 1,000$ million.

The government was expected to announce its intentions soon after the general election last June, but instead declared that a second committee would be set up to study Bide's proposals. It is suspected that the government is reluctant to provide such a large proportion of the total funding, given the 'near-market' nature of the envisaged programme.

Simon Hadlington

\title{
Japanese go-ahead for Cable and Wireless
}

cables stretching around the globe that will compete with networks operated by KDD, American Telephone and Telegraph (AT\&T) and British Telecom.

The ministry has said that it will grant IDC permission to lay the trans-Pacific cable, with a capacity equivalent to 11,000 telephone circuits, but the number of circuits licensed will be limited to prevent 'oversupply' in international telecommunications services - KDD and AT\&T plan to lay two trans-Pacific optical fibre cables that will compete with the IDC cable (see Nature 328, 477; 1987). A spokesman for Cable and Wireless says there is "nothing out of the ordinary" about this condition, in fact it was "expected".

Both IDC and ITJ plan to begin services in the spring of 1989, offering rates at least 20 per cent cheaper than KDD. In addition to the trans-Pacific cable, which should be in place by 1989-90, IDC will lease circuits on Intelsat satellites, while ITJ will lease circuits on the satellites and a trans-Pacific cable (TPC-3) that will be laid by KDD and AT\& T next year.

David Swinbanks \& Simon Hadlington 